\title{
Traumatic middle cerebral artery aneurysm: case report and review of the literature.
}

\author{
Tetsuyoshi Horiuchi, M.D. ${ }^{1,3}$, Fukuo Nakagawa, M.D. ${ }^{1}$, Masaki Miyatake, M.D. ${ }^{1}$, \\ Tomomi Iwashita, M.D. ${ }^{2}$, Yuichiro Tanaka, M.D. ${ }^{3}$, and Kazuhiro Hongo, M.D. ${ }^{3}$ \\ Department of Neurosurgery ${ }^{1}$, \\ Azumino Red Cross Hospital, \\ Azumino, Japan \\ Department of Intensive and Critical Care Medicine², \\ Shinshu University School of Medicine, \\ Matsumoto, Japan \\ Department of Neurosurgery ${ }^{3}$, \\ Shinshu University School of Medicine, \\ Matsumoto, Japan
}

\section{Correspondence to:}

Tetsuyoshi Horiuchi, M.D.

Department of Neurosurgery,

Shinshu University School of Medicine,

3-1-1 Asahi, Matsumoto 390-8621, Japan

Telephone: 81-263-37-2690

Fax: 81-263-37-0480

E-mail: thoriuchi-nsu@umin.ac.jp 


\begin{abstract}
Traumatic intracranial aneurysms are rare. A case of traumatic middle cerebral artery aneurysm was presented. A 66-year-old man sustained a severe head injury in a bicycle accident. Serial computed tomography and angiography showed the delayed intracerebral hemorrhage caused by the traumatic middle cerebral artery aneurysm. The aneurysm was trapped and removed. Histological examination clearly revealed the pseudoaneurysm. Traumatic middle cerebral aneurysms were reviewed.
\end{abstract}

Keywords: middle cerebral artery, surgery, traumatic aneurysm 


\section{Introduction}

Traumatic intracranial aneurysms rarely occur and can develop as the result of either blunt or penetrating head trauma. ${ }^{15 ; 26)}$ Traumatic intracranial aneurysms can present in a variety of ways such as subarachnoid hemorrhage, intracranial hemorrhage, and subdural hematoma. The mortality rate for patients with traumatic intracranial aneurysms is high up to $50 \%{ }^{16}$ Therefore, prompt diagnosis with cerebral angiography and sufficient surgical treatment are necessary. We present a case of traumatic middle cerebral artery aneurysm and review the literature.

\section{Case report}

A 66-year-old man sustained a severe head injury in a bicycle accident. The patient was knocked down by a motortruck. On arrival in the emergency room, the patient presented with consciousness disturbance (Glasgow Coma Scale: E1V1M4) and severe left hemiparesis. Examination revealed an open skull fracture at the right parietal region. Computed tomography (CT) revealed a brain contusion and traumatic subarachnoid hemorrhage with depressed skull fracture (Figure 1). A follow-up CT showed an enlargement of the hematoma at the fronto-temporal lobes and the contusional hematoma was removed with external decompression. Although the patient's condition was improving day by day, a follow-up CT revealed a delayed intracerebral hematoma on Day 7 (Figure 2). Cerebral angiograms detected a traumatic aneurysm at the peripheral middle cerebral artery (Figure 3). The aneurysm was trapped and removed. The postoperative course was uneventful. The patient made a favorite recovery after rehabilitation. Histological examination of the aneurysm showed the disruption of the arterial wall, so the diagnosis was the false aneurysm (Figure 4).

\section{Discussion}

In the present case, the traumatic aneurysm developed beneath the overlying depressed skull fracture and its rupture occurred on Day 7. The complete disruption of the arterial wall (false aneurysm) was clearly demonstrated on the histological findings.

Traumatic intracranial aneurysms are divided into 4 categories according to the mechanism of injury: following closed head injury, missile injury, penetrating head injury, and iatrogenic injury. ${ }^{27}$ Traumatic intracranial aneurysms usually affect in the supraclinoid segment of the internal carotid artery and the anterior cerebral artery. ${ }^{\mathbf{1 6} 26}$ Traumatic 
intracranial aneurysms are also classified histologically as true or false. True aneurysms are formed after a partial disruption of the arterial wall. The internal elastic lamina and media damages with an intact adventitia form the true aneurysm. The complete penetrating injury of the vessel wall results in the false aneurysm. The hematoma organizes to form the outer wall of the aneurysm. Unlike berry aneurysms, traumatic intracranial aneurysms typically do not have a neck, are more irregular in their dome contour, and are subject to delayed filling and emptying of the sac based on angiograms.

Clinical characteristics of traumatic middle cerebral artery aneurysms: Traumatic middle cerebral artery aneurysms are reviewed based on previous reports including the present one. We excluded traumatic aneurysms caused by weapons such as missile ${ }^{3 ; 7}$ and those following iatrogenic injury. $^{14 ; 20}$ Finally, 28 cases with 32 aneurysms were analyzed and summarized in Table 1.;2;4;5;8-11;13;17-19;21-25 The mean age of patients was 42.1 years and there appeared to be strong male predominance. Multiple traumatic aneurysms were found in 2 cases $^{22}$ and the rupture rate was $72.4 \%$. The time of rupture after trauma was 4.7 days and the delayed rupture after trauma had occurred in $46.7 \%$ of patients. The majority of aneurysms were located in cortical segments. The linear and depressed fracture were found in 34.8 and $21.7 \%$ of cases, respectively. Interestingly, $43.5 \%$ of patients had no skull fracture. The subdural hematoma compared with intracerebral hematoma was prominently caused by the aneurysmal rupture. By contrast, traumatic intracranial aneurysms related to missile injury are associated with intracerebral hematoma in $80 \%$ and subdural hematoma in $26 \%{ }^{12}$

Based on our review, surgical treatments were carried out in 20 patients and $75 \%$ of patients had favorable outcome. On the other hand, 37.5\% of patients underwent no surgical treatment had favorable outcome.

\section{Diagnosis and treatment of traumatic middle cerebral artery aneurysms: Cerebral} angiography should be essential in patients with acute neurological deterioration and the delayed cerebral or subdural hematoma after head injury. It is difficult to evaluate the asymptomatic traumatic middle cerebral artery aneurysm. Since traumatic middle cerebral artery aneurysms are very rare and can also occur after mild head injury, ${ }^{2}$ the timing and necessity of angiography are difficult to decide. Neurosurgeons keep in mind that the traumatic middle cerebral artery aneurysmal rupture can develop the chronic subdural hematoma. $^{2}$ 
Although the spontaneous healing of traumatic middle cerebral artery aneurysm was reported, ${ }^{4 ; 22}$ appropriate surgical treatment should be necessary because of high mortality and mobility. In Table 1, 44, 16, and $12 \%$ of patients with traumatic middle cerebral artery aneurysm were treated with excision, clipping, and coagulation, respectively. Usually, it was difficult to use a clip for aneurysmal obliteration because almost aneurysms (83.3\%) were pseudoaneurysm. For the distal traumatic middle cerebral artery aneurysms, surgical trapping and excision are recommended. In the case described here, trapping and excision were sufficient. On the other hand, the more proximal aneurysms should be treated with clipping, trapping with bypass, or endovascular techniques to preserve distal blood flow. 6;16 


\section{Reference List}

1. Acosta C, Williams PE, Jr., Clark K: Traumatic aneurysms of the cerebral vessels. J.Neurosurg. 36:531-536, 1972

2. Amagasa M, Onuma T, Suzuki J: [Pseudoaneurysm of the cortical artery associated with chronic subdural hematoma--a consideration on traumatic middle cerebral artery aneurysm]. No Shinkei Geka 15:81-86, 1987

3. Amirjamshidi A, Rahmat H, Abbassioun K: Traumatic aneurysms and arteriovenous fistulas of intracranial vessels associated with penetrating head injuries occurring during war: principles and pitfalls in diagnosis and management. A survey of 31 cases and review of the literature. J.Neurosurg. 84:769-780, 1996

4. Benoit BG, Wortzman G: Traumatic cerebral aneurysms. Clinical features and natural history. J.Neurol.Neurosurg.Psychiatry 36:127-138, 1973

5. Buckingham MJ, Crone KR, Ball WS, et al: Traumatic intracranial aneurysms in childhood: two cases and a review of the literature. Neurosurgery 22:398-408, 1988

6. Ditmore QM, Samson DS, Beyer CW: Traumatic middle cerebral artery aneurysm: case report. Neurosurgery 6:293-296, 1980

7. du T, van Dellen JR: Penetrating stab wounds to the brain: the timing of angiography in patients presenting with the weapon already removed. Neurosurgery 31:905-911, 1992

8. Eichler A, Story JL, Bennett DE, et al: Traumatic aneurysm of a cerebral artery. Case report. J.Neurosurg. 31:72-76, 1969

9. Fleischer AS, Patton JM, Tindall GT: Cerebral aneurysms of traumatic origin. Surg.Neurol. 4:233-239, 1975

10. Gelabert M, Bollar A, Allut AG, et al: Traumatic aneurysm of the middle cerebral artery. Clin.Neurol.Neurosurg. 91:75-77, 1989

11. Go KG, Penning L, Oen TS: Acute subdural haematoma in connection with angiographically demonstrated traumatic rupture of a cortical cerebral artery (presenting 
as false aneurysm. A report of 2 cases. Neuroradiology 2:107-110, 1971

12. Haddad FS, Haddad GF, Taha J: Traumatic intracranial aneurysms caused by missiles: their presentation and management. Neurosurgery 28:1-7, 1991

13. Iob I, Scanarini M, Salar G, et al: Traumatic cerebral aneurysm in pediatric age. Case report. J.Neurosurg.Sci. 27:187-190, 1983

14. Jenkinson MD, Basu S, Broome JC, et al: Traumatic cerebral aneurysm formation following ventriculoperitoneal shunt insertion. Childs Nerv.Syst. 22:193-196, 2006

15. Komiyama M, Morikawa T, Nakajima H, et al: "Early" apoplexy due to traumatic intracranial aneurysm--case report. Neurol.Med.Chir (Tokyo) 41:264-270, 2001

16. Larson PS, Reisner A, Morassutti DJ, et al: Traumatic intracranial aneurysms. Neurosurg.Focus. 8:e4, 2000

17. Miyazaki S, Fukushima H, Kamata K, et al: False aneurysm with subdural hematoma and symptomatic vasospasm following head injury. Surg.Neurol. 16:443-447, 1981

18. Murakami M, Kakita K, Hosokawa Y: Ruptured traumatic aneurysm after trivial injury mimicking acute spontaneous subdural hematoma--case report-. Neurol.Med.Chir (Tokyo) 43:130-133, 2003

19. Ohta M, Matsuno H: Proximal M2 false aneurysm after head trauma--Case report. Neurol.Med.Chir (Tokyo) 41:131-134, 2001

20. Overton MC, III, Calvin TH, Jr.: Iatrogenic cerebral cortical aneurysm. Case report. J.Neurosurg. 24:672-675, 1966

21. Parkinson D, West M: Traumatic intracranial aneurysms. J.Neurosurg. 52:11-20, 1980

22. Rumbaugh CL, Bergeron RT, Talalla A, et al: Traumatic aneurysms of the cortical cerebral arteries. Radiographic aspects. Radiology 96:49-54, 1970

23. Sedzimir CB, Occleshaw JV, Buxton PH: False cerebral aneurysm. Case report. J.Neurosurg. 29:636-639, 1968

24. Smith DR, Kempe LG: Cerebral false aneurysm formation in closed head trauma; case 
report. J.Neurosurg. 32:357-359, 1970

25. Tsubokawa T, Kotani A, Sugawara T, et al: [Treatment for traumatic aneurysm of the cerebral artery--identification between deteriorating type and spontaneously disappearing type (author's transl)]. No Shinkei Geka 3:663-672, 1975

26. Uzan M, Cantasdemir M, Seckin MS, et al: Traumatic intracranial carotid tree aneurysms. Neurosurgery 43:1314-1320, 1998

27. Ventureyra EC, Higgins MJ: Traumatic intracranial aneurysms in childhood and adolescence. Case reports and review of the literature. Childs Nerv.Syst. 10:361-379, 1994 


\section{Figure legends}

Figure 1: Computed tomography showing a brain contusion and subarachnoid hemorrhage. Note that the depressed skull fracture is seen.

Figure 2: Computed tomography showing an intracerebral hematoma at the right parietal lobe.

Figure 3: Right carotid angiograms (A and C: antero-posterior views, B and D: lateral views) showing the peripheral middle cerebral artery aneurysm (arrowheads).

Figure 4: Photomicrographs of the aneurysm showing the pseudoaneurysm. Note that the complete disruption of the arterial wall. Arrowhead and asterisk indicating the arterial wall and aneurysmal cavity, respectively. Hematoxylin and eosin stain, original magnification $\mathrm{x}$ 20 (A), x 40 (B), and x 100 (C). Elastica-van Gieson stain, original magnification x 100 (D) 
Table 1. Characteristics of patients with traumatic middle cerebral artery aneurysm

\begin{tabular}{|c|c|c|}
\hline Age (mean \pm SD) & $42.1 \pm 22.5$ ( 2 to 75$) \mathrm{y} / \mathrm{o}$ & $\mathrm{n}=28$ \\
\hline Sex: & & $\mathrm{n}=28$ \\
\hline Female & $17.9 \%$ & \\
\hline Male & $82.1 \%$ & \\
\hline Affected Side: & & $\mathrm{n}=28$ \\
\hline Right & $67.9 \%$ & \\
\hline Left & $32.1 \%$ & \\
\hline Ruptured aneurysm & $72.4 \%$ & $\mathrm{n}=29$ \\
\hline Time trauma to rupture & 4.7 (0 to 18$)$ days & $\mathrm{n}=15$ \\
\hline Size of aneurysm & 3 (1 to 4$) \mathrm{mm}$ & $\mathrm{n}=9$ \\
\hline Location: & & $\mathrm{n}=32$ \\
\hline Insular segment & $3.1 \%$ & \\
\hline Cortical segment & $93.8 \%$ & \\
\hline Not described & $3.1 \%$ & \\
\hline Skull fracture: & & $\mathrm{n}=23$ \\
\hline None & $43.5 \%$ & \\
\hline Linear & $34.8 \%$ & \\
\hline Depressed & $21.7 \%$ & \\
\hline Presentation of aneurysm: & & $\mathrm{n}=27$ \\
\hline SDH & $55.6 \%$ & \\
\hline $\mathrm{ICH}$ & $14.8 \%$ & \\
\hline $\mathrm{ICH}$ and SAH & $3.7 \%$ & \\
\hline Headache & $3.7 \%$ & \\
\hline Incidental & $22.2 \%$ & \\
\hline Surgical treatment: & & $\mathrm{n}=25$ \\
\hline Excision & $44 \%$ & \\
\hline Clipping & $16 \%$ & \\
\hline Coagulation & $12 \%$ & \\
\hline None & $28 \%$ & \\
\hline Pathology: & & $\mathrm{n}=12$ \\
\hline True & $16.7 \%$ & \\
\hline Pseudo & $83.3 \%$ & \\
\hline Outcome: & & $\mathrm{n}=28$ \\
\hline Favorable & $64.3 \%$ & \\
\hline Unfavorable & $35.7 \%$ & \\
\hline
\end{tabular}


Subdural hematoma: SDH, Intracerebral hematoma: ICH, SAH: subarachnoid hemorrhage, n: number of the patient or the aneurysm 